\title{
Preliminary Testing to Determine the Best Process Parameters for Polymer Laser Sintering of a New Polypropylene Polymeric Material
}

\author{
Fredrick M. Mwania $(\mathbb{D}$, Maina Maringa $(\mathbb{D}$, and Jakobus. G. van der Walt $\mathbb{C}$ \\ Department of Mechanical and Mechatronics Engineering, Central University of Technology, Free State, Private Bag X20539, \\ Bloemfontein 9300, South Africa
}

Correspondence should be addressed to Fredrick M. Mwania; fredmulinge@gmail.com

Received 3 December 2020; Revised 10 January 2021; Accepted 30 January 2021; Published 9 February 2021

Academic Editor: Bingang Xu

Copyright (c) 2021 Fredrick M. Mwania et al. This is an open access article distributed under the Creative Commons Attribution License, which permits unrestricted use, distribution, and reproduction in any medium, provided the original work is properly cited.

\begin{abstract}
Polymer laser sintering is an elaborate additive manufacturing technique because it is subject to process parameters and material properties. In this regard, each polymeric material necessitates a different set of process conditions. To this end, testing was done to determine the most suitable process parameters for a new commercially available polymer (Laser PP CP 60), from Diamond Plastics GmbH. It was established that the material requires slightly different settings from those provided by the supplier for the values for the removal chamber temperature, building chamber temperatures, and laser power to achieve the best mechanical properties (ultimate tensile strength). The preliminary testing indicates that the process parameters that yielded the best mechanical properties for the laser PP CP 60 powder were $125^{\circ} \mathrm{C}, 125^{\circ} \mathrm{C}, 0.15 \mathrm{~mm}, 250 \mu \mathrm{m}, 4500 \mathrm{~mm} / \mathrm{s}, 34.7 \mathrm{~W}$, $1500 \mathrm{~mm} / \mathrm{s}$, and $21.3 \mathrm{~W}$ for the removal chamber temperature, building chamber temperature layer thickness, hatch distance, scanning speed fill, laser power fill, scanning speed contour, and laser power contour, respectively.
\end{abstract}

\section{Introduction}

Polymer laser sintering (PLS) is a type of additive manufacturing technology that uses either a continuous or pulse mode laser beam to fuse powder particles to form 3dimensional parts from computer-aided data [1]. Polymer laser sintering is broadly referred to as selective laser sintering (SLS), which is described as a technology that uses a power source to sinter and bind powdered materials, such as polyamide or polypropylene [2]. The PLS technique has become widely popular for the processing of polymers because of its ability to achieve good geometrical accuracy, good surface finish, and excellent mechanical properties of the manufactured parts. In addition, the technology does not require the use of binders or support structures, as the powder on the build platform serves this purpose [3]. However, setting the process parameters to obtain the desired properties of polymeric materials is an intricate exercise $[4,5]$. This has led to a paucity of the available polymers for PLS and slowed the uptake of the technology in manufacturing of polymer components $[4,5]$.

Process parameters can be classified into laser-related factors, scan-related, and temperature-related parameters [6]. Some of the laser-related factors include wavelength, laser power, hatch distance, vector length, ratio of length to width, point overlapping, beam spatial distribution, continuous or pulsed laser operation, and beam diameter [5]. Some of the scan-related factors include scanning speed, scanning pattern, and scanning angle. The temperature-related parameters comprise the building chamber temperature and the removal chamber temperature [6].

The laser power, scanning speed, hatch distance, and layer thickness are the most easily adjustable process parameters in PLS. The four parameters determine the amount of laser energy that is transferred to the powder and are related to one another as shown by Equations (1) and (2) [5]. Previous studies have shown that increasing laser energy density increases part density and mechanical properties, but in turn 


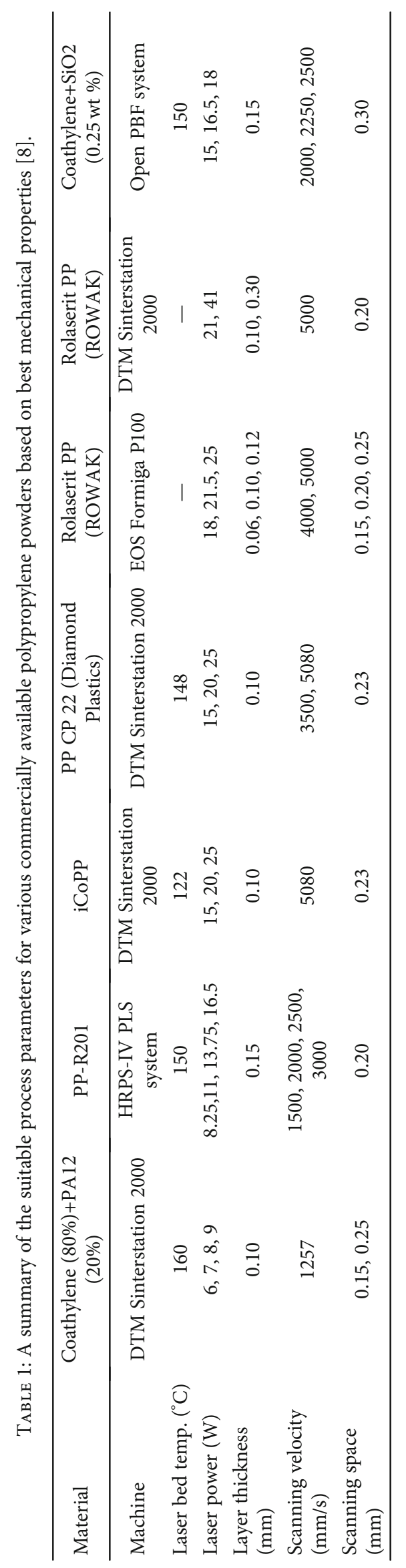


introduces curling, which affects the dimensional accuracy of the printed components [6].

$$
E=\frac{P}{V \times H},
$$

where $E=$ laser energy density $\left(\mathrm{J} / \mathrm{mm}^{2}\right), P=$ laser power $(\mathrm{J} / \mathrm{s})$, $V=$ laser scanning speed $(\mathrm{mm} / \mathrm{s})$, and $H=$ hatch distance $(\mathrm{mm})$

$$
V=\frac{P}{V \times H \times D}
$$

where $V=$ volumetric laser energy density $\left(\mathrm{J} / \mathrm{mm}^{3}\right), P=$ laser power $(\mathrm{J} / \mathrm{s}), V=$ laser scan speed $(\mathrm{mm} / \mathrm{s}), H=$ hatch distance $(\mathrm{mm})$, and $D=$ layer thickness $(\mathrm{mm})$.

The objective of the work reported here was to determine the best process parameters for a new commercial polymeric polypropylene powder for PLS ((Laser PP CP 60 from Diamond Plastics $\mathrm{GmbH}$ ). The following process parameters were considered: removal chamber temperature, building chamber temperature, scanning speed fill, laser power fill, scanning speed contour, and laser power contour. The scanning speed fill is the speed of the laser beam as it scans the area of the part in each layer, whereas the scanning speed contour is the speed of the laser beam as it scans the edges of the part in each layer. The laser power fill is the power of the laser beam as it scans the area of the part in each layer, whereas the laser power contour is the power of the laser beam as it scans the edges of the part in each layer. The removal chamber temperature is set to ensure that printed parts cool at a regulated rate, while the building chamber temperature is set to ensure that the powder layer is preheated to a temperature just below the melting point of the material before sintering.

\section{Literature Review}

2.1. Polymer Laser Sintering Process Parameters of Some Commercially Available Polymers. Flores et al. [7] conducted research on polypropylene to characterize the material and obtain the most suitable process parameters. The test material was a mechanically mixed Coathylene ${ }^{\circledR}$ SINT polypropylene powder from Axalta Polymer Powders. The sintering machine was not a commercial machine, but it was designed based on the architecture of commercial laser sintering equipment. It was found that the best mechanical properties of the sintered parts were achieved at energy densities between $0.100 \mathrm{~J} / \mathrm{mm}^{3}$ and $0.122 \mathrm{~J} / \mathrm{mm}^{3}$, laser power between $15 \mathrm{~W}$ and $17 \mathrm{~W}$, and scanning speed between $2250 \mathrm{~mm} / \mathrm{s}$ and $2500 \mathrm{~mm} / \mathrm{s}$. The authors further provided a summary of the process parameters for various polypropylene powders as summarized in Table 1.

Sequeira et al. [9] carried out an experiment to establish suitable process parameters for polyethylene obtained from Oswal Hi-tech in Bangalore with an average particle size of $150 \mu \mathrm{m}$. It was concluded that the most suitable processing conditions for this polyethylene powder were laser power of $22.5 \mathrm{~W}$, hatch spacing of $0.3 \mathrm{~mm}$, scanning speed of

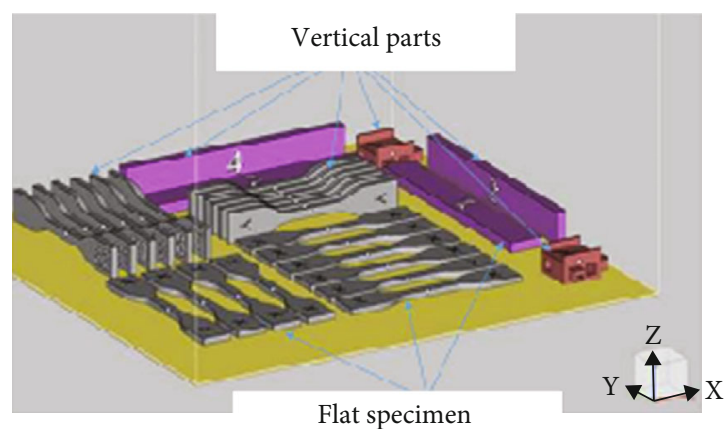

FIgURE 1: Orientation of the test coupons used to determine the best building chamber and removal chamber temperatures.

$500 \mathrm{~mm} / \mathrm{s}$, spot beam diameter of $1.5 \mathrm{~mm}$, and laser volumetric energy density of $1.5 \mathrm{~J} / \mathrm{mm}^{3}$.

Goodridge et al. [10] conducted an analysis to determine the feasibility of processing ultrahigh molecular weight polyethylene (UHMWPE) using a commercial laser sintering machine (Vanguard Laser Sintering Machine from 3D Systems). The authors found that multiple layer components could be printed using UHMWPE material at a laser bed temperature of $135^{\circ} \mathrm{C}$, feed temperature (temperature of the feed chambers) of $125^{\circ} \mathrm{C}$, scanning speed of $5000 \mathrm{~mm} / \mathrm{s}$, hatch spacing of $150 \mu \mathrm{m}$, layer thickness of $100 \mu \mathrm{m}$, and laser power of 16-18 W.

Singh et al. [11] performed an analysis to establish the best processing conditions to maximize the density and hardness of parts developed using Duraform polyamide from 3D Systems Corporation. It was determined that optimum parameters were laser power of $24 \mathrm{~W}$, hatch distance of $100 \mu \mathrm{m}$, laser bed temperature of $173.65^{\circ} \mathrm{C}$, and double laser exposure.

Wang et al. [12] performed an experiment to determine the impact of various processing factors on warpage of polystyrene. A HRPS-IV rapid prototyping system was used in the study. The researchers proposed the following process parameters for polystyrene polymeric material: laser power $(12-24 \mathrm{~W})$, scanning speed $(1200-2600 \mathrm{~mm} / \mathrm{s})$, layer thickness $(140-240 \mu \mathrm{m})$, and hatch distance $(90-170 \mu \mathrm{m})$.

Berretta et al. [13] carried out a study to establish the processability of polyether ether ketone polymer (PEEK). PEEK $450 \mathrm{PF}$ from Victrex was utilized in the analysis, where it was found that the material can be processed using an EOSINT P 800 system at laser power of $6.8 \mathrm{~W}$ and scanning speed of $1000 \mathrm{~mm} / \mathrm{s}$ for contours and a laser power of $12 \mathrm{~W}$ with a scanning speed of $250 \mathrm{~mm} / \mathrm{s}$ and hatch distance of $200 \mu \mathrm{m}$. The powder bed temperature for PEEK 450PF was established as $\left(250-260^{\circ} \mathrm{C}\right)$.

Research done at the Centre for Rapid Prototyping and Manufacturing (CRPM) at the Central University of Technology, Free State, South Africa showed that the most suitable processing conditions for both polyamide 12 (PA 2200) and Alumide, from EOS $\mathrm{GmbH}$ were scanning fill speed $(4000 \mathrm{~mm} / \mathrm{s})$, scanning contour speed $(700 \mathrm{~mm} / \mathrm{s})$, laser power fill $(43 \mathrm{~W})$, laser power contour $(10 \mathrm{~W})$, building chamber temperature $\left(175^{\circ} \mathrm{C}\right)$, and chamber removal 
TABLE 2: Test parameters to determine the best removal chamber and building chamber temperatures for Laser PP CP 60 powder.

\begin{tabular}{|c|c|c|c|c|c|c|c|c|}
\hline Cycle & $\begin{array}{l}\text { Temp. of the } \\
\text { removal chamber } \\
\left({ }^{\circ} \mathrm{C}\right)\end{array}$ & $\begin{array}{l}\text { Temp. of the } \\
\text { building chamber } \\
\left({ }^{\circ} \mathrm{C}\right)\end{array}$ & $\begin{array}{c}\text { Layer } \\
\text { thickness } \\
(\mathrm{mm})\end{array}$ & $\begin{array}{c}\text { Hatch } \\
\text { distance } \\
(\mathrm{mm})\end{array}$ & $\begin{array}{c}\text { Scanning } \\
\text { speed fill } \\
(\mathrm{mm} / \mathrm{s})\end{array}$ & $\begin{array}{c}\text { Laser } \\
\text { power fill } \\
(\mathrm{W})\end{array}$ & $\begin{array}{c}\text { Scanning speed } \\
\text { contour/edges } \\
(\mathrm{mm} / \mathrm{s})\end{array}$ & $\begin{array}{c}\text { Laser power } \\
\text { contour/edges } \\
(\mathrm{W})\end{array}$ \\
\hline 1 & 100 & 120 & 0.15 & 0.25 & 4500 & 32.6 & 1500 & 19.8 \\
\hline 2 & 115 & 125 & 0.15 & 0.25 & 4000 & 32.6 & 1500 & 19.8 \\
\hline 3 & 120 & 130 & 0.15 & 0.25 & 4000 & 32.6 & 1500 & 19.8 \\
\hline 4 & 120 & 125 & 0.15 & 0.25 & 4000 & 33.7 & 1500 & 15.3 \\
\hline 5 & 120 & 125 & 0.15 & 0.25 & 3000 & 33.7 & 1000 & 15.3 \\
\hline 6 & 125 & 125 & 0.15 & 0.25 & 4500 & 33.7 & 1500 & 15.3 \\
\hline 7 & 124 & 125 & 0.15 & 0.25 & 4500 & 33.7 & 1500 & 15.3 \\
\hline
\end{tabular}

temperature $\left(135^{\circ} \mathrm{C}\right)$. CRPM uses EOSINT P 380, EOSINT P 385, and EOSINT P 396 machines.

Moreover, a study by Nsengimana et al. [14] established the most suitable scanning speed for CP 75 PP powder from Diamond Plastics GmbH. The researchers used an EOS P380 LS machine. The authors found the optimal values to attain acceptable mechanical properties, surface finish, as well as dimensional accuracy to range from 1481 to $1600 \mathrm{~mm} / \mathrm{s}$.

The foregoing review of the PLS process parameters of most of the commonly used polymeric materials highlights the fact that process parameters vary widely as a function of material and PLS equipment. This article articulates the results of a preliminary study performed to determine the best PLS process parameters for Laser PP CP 60 (polypropylene powder) from Diamond Plastics $\mathrm{GmbH}$.

\subsection{Suitable Material Properties for PLS Polymeric Powders.} Polymers applicable to the PLS should possess appropriate intrinsic and extrinsic properties. The material-properties of polymers considered in PLS are categorized into either intrinsic or extrinsic characteristics $[4,15]$. Extrinsic properties include the powder particle size, morphology, and powder density, while the intrinsic properties comprise the optical, rheological (viscosity and surface tension), and thermal (melting point and sintering window) properties. The impacts of the various material-attributes of polymers in PLS are well detailed in $[4,7,8,15,16]$. This analysis focuses on the process parameters of a newly introduced polypropylene powder (Laser PP CP 60 from Diamond Plastics $\mathrm{GmbH}$ ).

Suitable particle size distribution and morphology for PLS polymers should be approximately spherical to encourage as near free-flowing characteristics as possible [4]. Besides, appropriate PLS polymer powders should have a powder distribution approximately between $20 \mu \mathrm{m}$ and $80 \mu \mathrm{m}$ because extremely small particles induce stickiness, which reduces flowability [4, 17]. Large particles on the other hand discourage fusion, which introduces porosity and in turn reduces the mechanical integrity of printed parts [15].

PLS polymers should have a high-temperature degradation point to prevent deterioration because the process occurs under high temperatures [6]. Besides, processing temperatures should be maintained between the melting point and crystallization point of polymeric materials to prevent rapid solidifica-

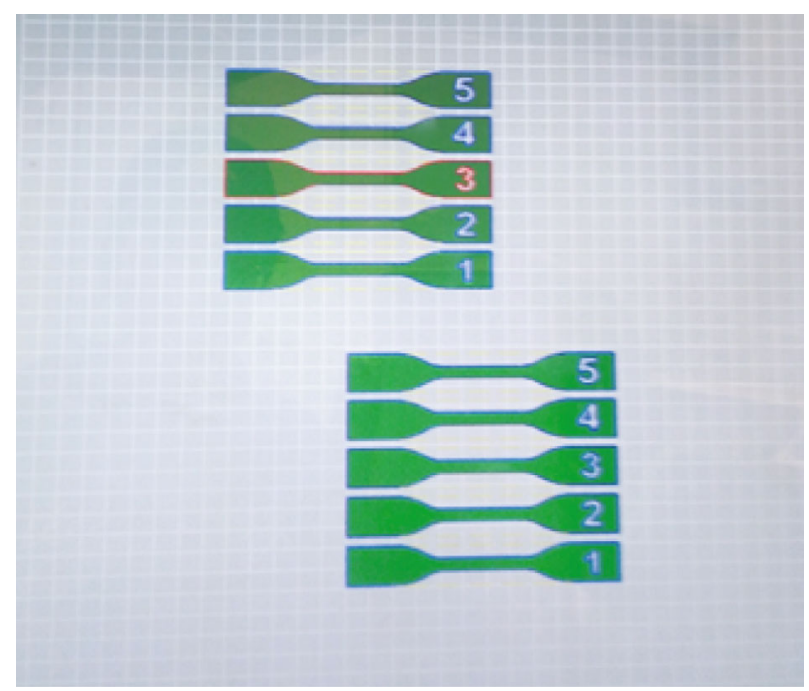

Figure 2: Orientation of the labelled test specimens (ASTM D 638).

tion of printed parts, which is likely to affect the geometrical accuracy as well as the surface finish of the manufactured components $[3,6]$. The difference between the melting point and crystallization point is known as the sintering-window $[3,6]$. Appropriate PLS polymers should have a wide and sufficient sintering-window $\left(20-30^{\circ} \mathrm{C}\right)$, which prevents crystallization of the polymers during processing $[3,6]$. Suitable polymers should have a narrow melting point region to prevent the use of high laser energy when fusing the particles of powder [3]. High laser energy leads to greater degradation of the powder supporting the components being printed, which limits the recyclability of the powder [6]. Therefore, the thermal properties of powders significantly determine acceptable polymers for the SLS process.

A suitable polymeric melt should have low viscosity and low surface tension to ensure adequate fusion of the particles of powder $[4,18,19]$. Extremely low melt viscosity compromises the surface roughness of printed components because the melt seeps into the surrounding support-powder [3]. Besides, it important for the powder to have low melt viscosity with low shear stress [4]. Low powder particle surface tension encourages better flowability of the material. Thus, viscosity, surface tension, and shear stress form an important material-property requirement for PLS polymers. 
TABLE 3: The process parameters used to build different standard tensile specimens (ASTM D 638).

\begin{tabular}{lcccccccc}
\hline Specimen & $\begin{array}{c}\text { Temp. of the } \\
\text { removal chamber } \\
\left({ }^{\circ} \mathrm{C}\right)\end{array}$ & $\begin{array}{c}\text { Temp. of the } \\
\text { building chamber } \\
\left({ }^{\circ} \mathrm{C}\right)\end{array}$ & $\begin{array}{c}\text { Layer } \\
\text { thickness } \\
(\mathrm{mm})\end{array}$ & $\begin{array}{c}\text { Hatch } \\
\text { distance } \\
(\mathrm{mm})\end{array}$ & $\begin{array}{c}\text { Scanning } \\
\text { speed fill } \\
(\mathrm{mm} / \mathrm{s})\end{array}$ & $\begin{array}{c}\text { Laser } \\
\text { power fill } \\
(\mathrm{W})\end{array}$ & $\begin{array}{c}\text { Scanning speed } \\
\text { contour/edges } \\
(\mathrm{mm} / \mathrm{s})\end{array}$ & $\begin{array}{c}\text { Laser power } \\
\text { contour/edges } \\
(\mathrm{W})\end{array}$ \\
\hline 1 & 125 & 125 & 0.15 & 0.25 & 2000 & 23.3 & 700 & 9.7 \\
2 & 125 & 125 & 0.15 & 0.25 & 2500 & 25.5 & 700 & 13.0 \\
3 & 125 & 125 & 0.15 & 0.25 & 2500 & 30.2 & 700 & 13.0 \\
4 & 125 & 125 & 0.15 & 0.25 & 3500 & 31.5 & 1500 & 1500 \\
5 & 125 & 125 & 0.15 & 0.25 & 4500 & 34.7 & 21.3 \\
\hline
\end{tabular}

Optical properties also affect the PLS process. Thus, a suitable polymeric material should absorb enough laser energy to ensure satisfactory fusion of the powder particles. Most polymers absorb the laser energy of the commonly utilized $\mathrm{CO}_{2}$ laser with a wavelength of about $10 \mu \mathrm{m}$, sufficiently $[4,20]$. Therefore, the issue of optical properties is not a major hindrance for selective laser sintering of polymers.

Most polymeric materials do not meet the requirements for PLS, which has led to the small variety of polymers that are used in this type of AM. As a result, the cost of PLS polymers is relatively high (one kilogram of PP powder from Diamond Plastics costs about 60 Euros) compared to the feedstock of the same material used in conventional manufacturing, such as in injection moulding, which is 20 times less expensive [3]. Thus, the need to introduce new polymeric materials to reduce feedstock cost in order to encourage the uptake of the technology. The present study focused on determining process parameters of virgin Laser PP CP 60 polypropylene material from Diamonds Plastics, $\mathrm{GmbH}$ based on a preliminary testing. According to Marin [6], appropriate PLS polymers should have the following:

(1) A low melt viscosity at low shear stresses

(2) A wide temperature range between melting and degradation temperatures

(3) A sufficient temperature range between melting and crystallization point

(4) Sufficient dry-flow and melt-flow characteristics

(5) Low moisture sensitivity

(6) No significant emission of volatiles during processing

(7) Suitable thermal properties

(8) Approximately spherical particles that preferably are less than $100 \mu \mathrm{m}$ in size and finally the polymers should

(9) Not fuse together or segregate during storage

2.3. Potential Defects due to Incorrect Parameters Used. Process parameters influence the mechanical properties, density, hardness, porosity, surface roughness, and the dimensional accuracy of the printed parts [5]. Therefore, optimizing the process parameters is crucial in meeting part requirements. Moreover, most of these process parameters are related to each other. For example, a low powder bed temperature requires a

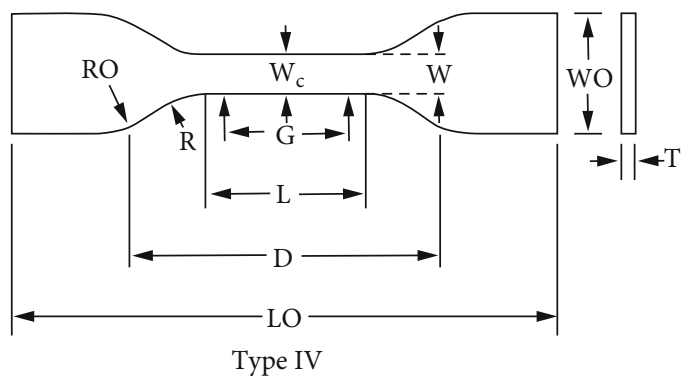

FIgURE 3: Standard tensile specimen (ASTM D 638) [21].

TABLE 4: The standard tensile specimen dimensions (ASTM D 638) [21].

\begin{tabular}{lc}
\hline Parameter & Dimension $(\mathrm{mm})$ \\
\hline T (thickness) & 4 \\
W (width of narrow section) & 6 \\
WO (width overall) & 19 \\
LO (length overall) & 115 \\
G (gage length) & 25 \\
D (distance between grips) & 65 \\
R (radius of fillet) & 14 \\
RO (outer radius) & 25 \\
\hline
\end{tabular}

high laser power and vice versa [6]. In addition, a combination of high powder bed temperature and laser power results in dense parts. However, it compromises the recyclability of the un-sintered powder due to over baking of the powder. Conversely, low power bed temperature result in components with better dimensional accuracy, but with low density and delamination of layers [6]. Furthermore, low powder bed temperatures and removal chamber temperatures promote part curling, thus affecting the dimensional accuracy of the components and might, in extreme cases, halt the printing process as the recoater blade dislodges parts from the powder bed [16] Low laser power requires low scanning speeds, while high laser power requires high scanning speeds to ensure complete fusion of the powder particles [6]. Improper bonding of powder particles encourages porosity, which undermines the mechanical strength of printed articles [6].

\section{Methodology}

3.1. Determining the Best Removal Chamber and Building Chamber Temperatures for Laser PP CP 60 Powder. The best 
TABle 5: Parameters and observations made while establishing optimal removal and building chamber temperature.

\begin{tabular}{|c|c|c|c|c|c|c|c|c|c|}
\hline $\begin{array}{l}\text { Set of } \\
\text { process } \\
\text { parameters \# }\end{array}$ & $\begin{array}{c}\text { Temp. } \\
\text { removal } \\
\text { chamber }\left({ }^{\circ} \mathrm{C}\right)\end{array}$ & $\begin{array}{c}\text { Temp. } \\
\text { building } \\
\text { phase }\left({ }^{\circ} \mathrm{C}\right)\end{array}$ & $\begin{array}{c}\text { Layer } \\
\text { thickness } \\
(\mathrm{mm})\end{array}$ & $\begin{array}{l}\text { Hatch } \\
\text { distance } \\
(\mathrm{mm})\end{array}$ & $\begin{array}{c}\text { Scan } \\
\text { speed fill } \\
(\mathrm{mm} / \mathrm{s})\end{array}$ & $\begin{array}{c}\text { Laser } \\
\text { power fill } \\
(\mathrm{W})\end{array}$ & $\begin{array}{c}\text { Scan speed } \\
\text { contour/edges } \\
(\mathrm{mm} / \mathrm{s})\end{array}$ & $\begin{array}{c}\text { Laser power } \\
\text { contour/edges } \\
(\mathrm{W})\end{array}$ & Observation \\
\hline 1 & 100 & 120 & 0.15 & 0.25 & 4500 & 32.6 & 1500 & 19.8 & $* *$ \\
\hline 2 & 115 & 125 & 0.15 & 0.25 & 4000 & 32.6 & 1500 & 19.8 & $* *$ \\
\hline 3 & 120 & 130 & 0.15 & 0.25 & 4000 & 32.6 & 1500 & 19.8 & $* *$ \\
\hline 4 & 120 & 125 & 0.15 & 0.25 & 4000 & 33.7 & 1500 & 15.3 & $* *$ \\
\hline 5 & 120 & 125 & 0.15 & 0.25 & 3000 & 33.7 & 1000 & 15.3 & $* *$ \\
\hline 6 & 125 & 125 & 0.15 & 0.25 & 4500 & 33.7 & 1500 & 15.3 & ++ \\
\hline 7 & 124 & 125 & 0.15 & 0.25 & 4500 & 33.7 & 1500 & 15.3 & $* *$ \\
\hline
\end{tabular}

${ }^{* *}$ Flat specimens were not grown to completion. ${ }^{++}$Flat specimens were grown to completion.

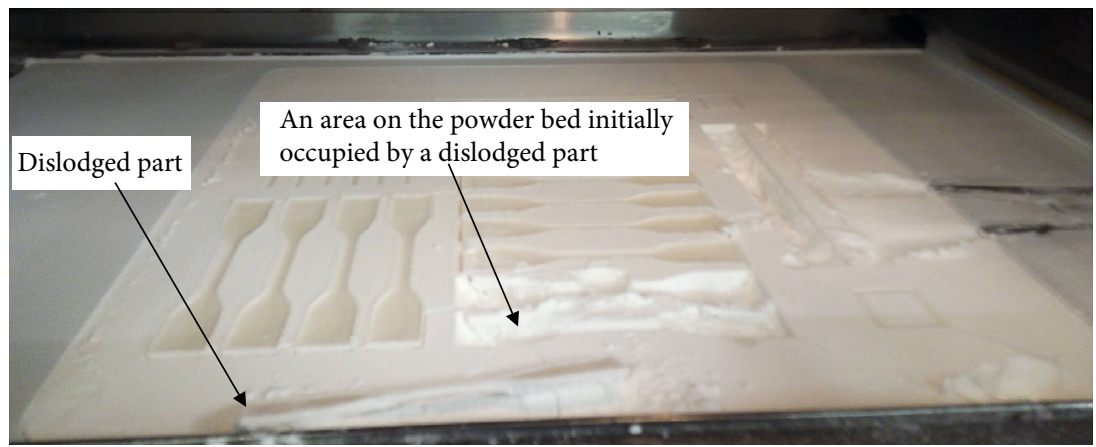

Figure 4: Printed parts on the powder bed, showing minimal curling visible on the edges and parts dislodged from their positions by the recoater blade.

TABLE 6: Some mechanical properties of the built test specimens.

\begin{tabular}{|c|c|c|c|c|c|c|c|c|c|}
\hline Specimen & $\begin{array}{c}\text { Elastic } \\
\text { Modulus } \\
(\mathrm{MPa})\end{array}$ & $\begin{array}{c}\text { Manufacture's } \\
\text { value (MPa) }\end{array}$ & $\begin{array}{c}\text { Percentage } \\
\text { difference } \\
(\%)\end{array}$ & $\begin{array}{c}\text { Percentage } \\
\text { elongation } \\
(\%)\end{array}$ & $\begin{array}{c}\text { Manufacture's } \\
\text { value (\%) }\end{array}$ & $\begin{array}{c}\text { Percentage } \\
\text { difference } \\
(\%)\end{array}$ & $\begin{array}{c}\text { Ultimate } \\
\text { tensile } \\
\text { strength } \\
(\mathrm{MPa})\end{array}$ & $\begin{array}{c}\text { Manufacture's } \\
\text { value (MPa) }\end{array}$ & $\begin{array}{c}\text { Percentage } \\
\text { difference } \\
(\%)\end{array}$ \\
\hline 1 & 582.8 & 1000 & 41.72 & 426.5 & 26 & 93.90 & 18.4 & 25 & 26.40 \\
\hline 2 & 698.8 & 1000 & 30.12 & 470.1 & 26 & 94.46 & 20.0 & 25 & 20.00 \\
\hline 3 & 635.5 & 1000 & 36.45 & 483.2 & 26 & 94.62 & 19.5 & 25 & 22.00 \\
\hline 4 & 659.2 & 1000 & 34.08 & 462.7 & 26 & 94.38 & 18.0 & 25 & 28.00 \\
\hline 5 & 668.4 & 1000 & 33.16 & 507.4 & 26 & 94.88 & 21.2 & 25 & 15.20 \\
\hline
\end{tabular}

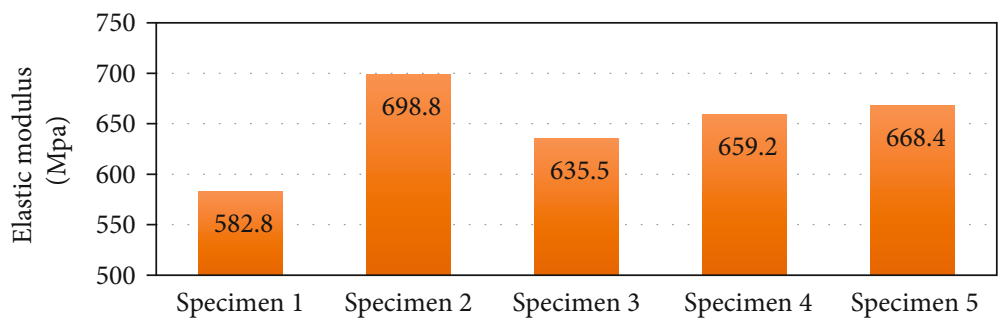

FIgURE 5: Comparison of the elastic modulus for the printed specimen.

building chamber and removal chamber temperatures were established, before embarking on the determination of suitable process parameters in terms of laser power fill, laser power contour, scanning speed fill, and scanning speed con- tour. This was carried out by observing the spreading of the fresh virgin powder on the build platform and also by inspecting the printed parts for curling and its absence. Each build process involved first preheating the process chamber 


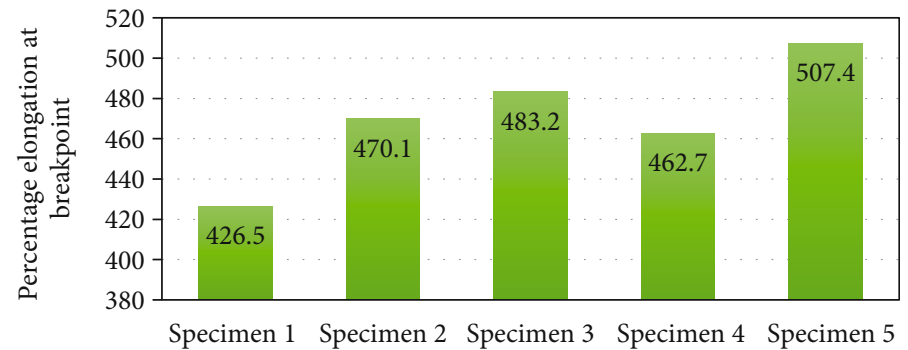

Figure 6: Comparison of the percentage elongation \% for the printed specimen.

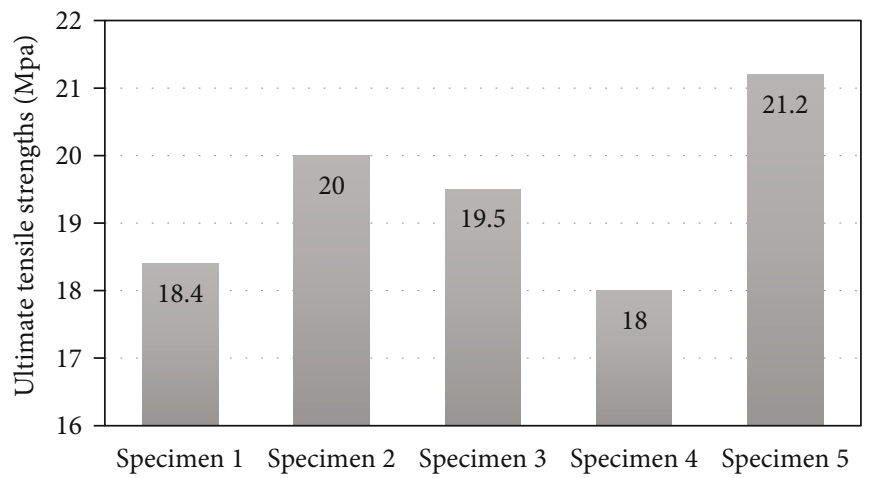

FiguRE 7: Comparison of the ultimate tensile strength for the printed specimen.

TABLE 7: Experimentally determined and manufacturer's process parameters for Laser PP CP 60, based on mechanical properties of built tensile test specimens.

\begin{tabular}{|c|c|c|c|c|c|c|c|c|}
\hline & $\begin{array}{l}\text { Temp. of the } \\
\text { removal } \\
\text { chamber }\left({ }^{\circ} \mathrm{C}\right)\end{array}$ & $\begin{array}{l}\text { Temp. of the } \\
\text { building bed } \\
\left({ }^{\circ} \mathrm{C}\right)\end{array}$ & $\begin{array}{c}\text { Layer } \\
\text { thickness } \\
(\mathrm{mm})\end{array}$ & $\begin{array}{l}\text { Hatch } \\
\text { distance } \\
(\mathrm{mm})\end{array}$ & $\begin{array}{c}\text { Scanning } \\
\text { speed fill } \\
(\mathrm{mm} / \mathrm{s})\end{array}$ & $\begin{array}{c}\text { Laser } \\
\text { power fill } \\
\text { (W) }\end{array}$ & $\begin{array}{l}\text { Scanning speed } \\
\text { contour/edges } \\
(\mathrm{mm} / \mathrm{s})\end{array}$ & $\begin{array}{c}\text { Laser power } \\
\text { contour/edges } \\
(\mathrm{W})\end{array}$ \\
\hline $\begin{array}{l}\text { Experimentally } \\
\text { determined } \\
\text { parameters }\end{array}$ & 125 & 125 & 0.15 & 0.25 & 4500 & 34.7 & 1500 & 21.3 \\
\hline $\begin{array}{l}\text { Manufacturer } \\
\text { specified } \\
\text { parameters }\end{array}$ & 115 & $120-125$ & 0.15 & 0.25 & 4500 & 35.0 & 1500 & 20.0 \\
\hline
\end{tabular}

for 120 minutes. Then, the fresh polypropylene powder was deposited on the machine's building platform to a depth (layer thickness) of six millimeters prior to printing a set of test coupons as shown in Figure 1.

The parameters for different cycles in the series of builds carried out are shown in Table 2.

3.2. Determining the Mechanical Properties of Built Parts. Once the most appropriate building chamber and the removal chamber temperatures were established, different standard tensile specimens (ASTM D 638) were printed. These specimens were oriented in the building chamber as presented in Figure 2.

The values of laser power fill, laser power contour, scanning speed fill, and scanning speed contour used to build each specimen are given in Table 3 . The variations in the last four columns of the table were introduced from the operator's feel of the process, arising from years of use of the AM EOSINT P380 machine with polymer powders.
The printed specimens, at different process parameters, were subjected to tensile testing, surface roughness, and dimensional accuracy tests to determine suitable process parameters for Laser PP CP 60. The built specimens were tested using a MTS Criterion ${ }^{\mathrm{TM}}$, Model 43 universal testing machine under ASTM D 638 standards at $1.5 \mathrm{~mm} /$ minute speed rate [21].

3.3. Determining the Physical Property of Surface Roughness. The experiment begun by calibrating the surface roughness measuring tester (SJ-210), as described in the user manual. The tester was then connected to the display and the Surftest software launched. The ISO 4287: 1997 standards and a measuring distance of $2.5 \mathrm{~mm}$ were used during testing to measureRa value. The surface roughness of at least eight random areas on the top and bottom surfaces of each of the specimens was recorded and averages obtained. The $R a$ measurement represents the mean arithmetic deviation of the examined profile, $R z$ measurement the greatest height of 
TABLE 8: Surface roughness of built test specimens.

\begin{tabular}{|c|c|c|c|c|}
\hline & & & Average & Standard deviation \\
\hline \multirow{2}{*}{ Specimen 1} & Top surface & $R a(\mu \mathrm{m})$ & 20.206 & 4.302 \\
\hline & Bottom surface & $R a(\mu \mathrm{m})$ & 19.476 & 2.043 \\
\hline \multirow{2}{*}{ Specimen 2} & Top surface & $R a(\mu \mathrm{m})$ & 21,009 & 5.589 \\
\hline & Bottom surface & $R a(\mu \mathrm{m})$ & 15.038 & 1.450 \\
\hline \multirow{2}{*}{ Specimen 3} & Top surface & $R a(\mu \mathrm{m})$ & 20.198 & 4.014 \\
\hline & Bottom surface & $R a(\mu \mathrm{m})$ & 20.075 & 2.382 \\
\hline \multirow{2}{*}{ Specimen 4} & Top surface & $R a(\mu \mathrm{m})$ & 19.616 & 3.277 \\
\hline & Bottom surface & $R a(\mu \mathrm{m})$ & 14.957 & 2.190 \\
\hline \multirow{2}{*}{ Specimen 5} & Top surface & $R a(\mu \mathrm{m})$ & 20.743 & 4.049 \\
\hline & Bottom surface & $R a(\mu \mathrm{m})$ & 16.652 & 3.359 \\
\hline
\end{tabular}

the profile unevenness, and $R q$ measurement the depth of the largest profile depression [22, 23]. Small values of these three indicators of surface roughness denote smooth surfaces. The $\mathrm{Ra}$ value was used to assess roughness because it provides a general representation of the overall surface roughness of a component.

3.4. Determining the Dimensional Accuracy of the Printed Parts. The dimensional accuracy of the printed parts was determined by measuring different sections of the specimen, as shown in Figure 3. An electronic Vernier caliper was used to measure the width of the narrow section (W), width overall (WO), and length overall (LO). The measurements obtained were compared to the dimensions of the standard parts as specified in ASTM D 638, presented in Table 4.

\section{Results and Discussion}

4.1. Determining the Best Building Chamber and Removal Chamber Temperatures. The process parameters and observations made in the process of optimizing the build and removal chamber temperatures are presented in Table 5.

Seven different sets of process parameters were considered based on the operator's experience. It was observed that in all these sets of process parameters, the specimens specified in Figure 1 were not printed to completion except for the $6^{\text {th }}$ set of process parameters, where the flat specimens were grown to completion. Figure 4 shows dislodged printed parts during the processing phase.

Figure 4 presents images of the build for the $1^{\text {st }}$ set of process parameters. Similar behaviour was seen for all the other sets of process parameters except for the $6^{\text {th }}$ one. The problem of dislodging of the components was due to the curling observed on the edges of the printed parts. Curling is linked to low removal chamber temperatures, which facilitate rapid cooling of the built specimens and as a result cause curling of the edges of the printed parts [16]. Suitable polymers are characterized by a wide and sufficient sintering-window, which prevents crystallization of the polymers during processing $[3,6]$. Rapid crystallization of printed components is a major hurdle in PLS because it encourages curling, which in turn, affects the surface finish and dimensional accuracy of the produced parts [4]. Curling might also stop the PLS process as observed in this case. Low powder bed temperatures and removal chamber temperatures promote part curling, thus affecting the dimensional accuracy of the components and might, in extreme cases, halt the printing process as the recoater blade dislodges parts from the powder bed [16]. Further work is necessary to establish which combination of these three factors is determining for the powder under investigation presently.

The dislodging of the components was a result of the recoater blade picking the curled components as it moved across the powder bed. It was decided that the removal and building chamber temperatures used for the $6^{\text {th }}$ set of process parameters should be used to determine the best laser power and scanning speed for processing PLS Laser PP CP 60. Furthermore, it was decided that since this was a preliminary testing, further research would be conducted where only the removal and building chamber temperatures were varied separately, while all the other parameters were held constant. This is expected to confirm whether this set of process parameters was optimal with respect to the temperatures of the build and removal chambers.

4.2. The Mechanical Properties of Built Test Specimens. Table 6 presents the mechanical properties of fivespecimens that were printed using different laser power and scanning speed process parameters given in Table 3 .

The experimental values of mechanical properties are seen in Table 6 to be lower than the values from the manufacturer, with the highest percentage differences being for the stiffness. This might be attributed to insufficient fusion of the power particles due to lower laser energy density, which normally results in the introduction of porosity and in turn reduces the mechanical integrity of printed parts [6]. Previous studies have shown that increasing laser energy density increases part density and mechanical properties [6]. The reduction of mechanical properties might also have been caused by a high melt viscosity of the new polymeric powder, which lowers the coalescence of particles of powder, thus leading to increased porosity, and in turn, undermines the mechanical strength of printed parts [13]. However, the percentage elongation to failure was significantly higher, $94 \%$ 


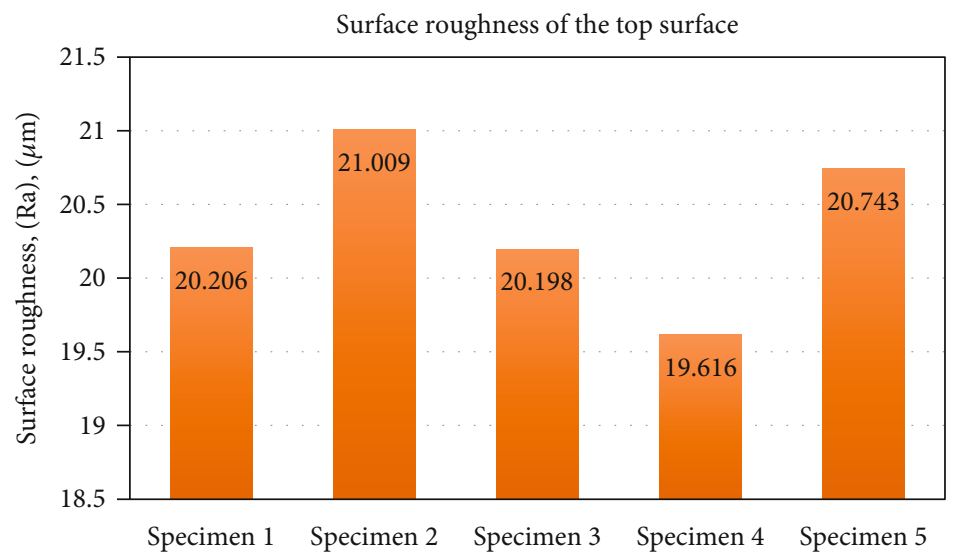

FIGURE 8: The mean arithmetic deviation $(R a)$ of the top surface of the specimens.

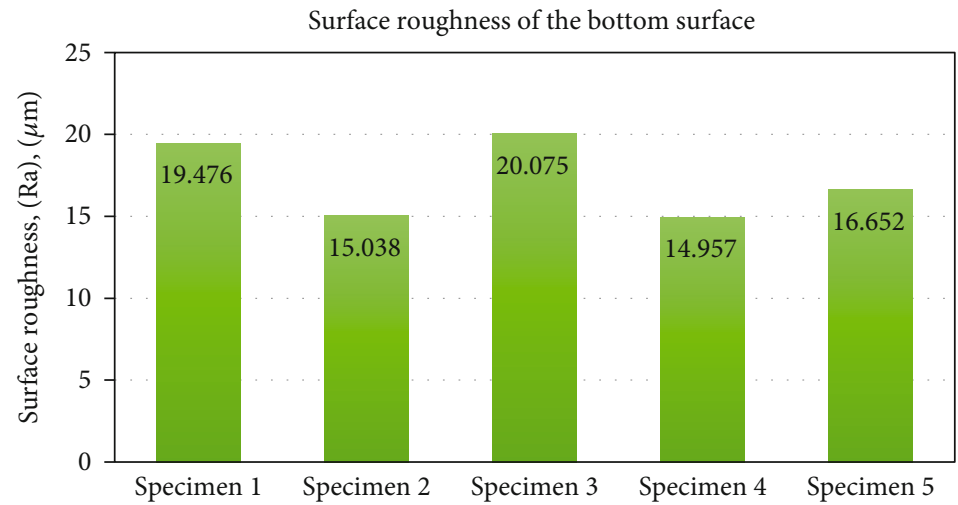

Figure 9: The mean arithmetic deviation $(R a)$ of the bottom surface of the specimens.

TABLE 9: Experimentally determined best process parameters for Laser PP CP 60 based on surface roughness.

\begin{tabular}{|c|c|c|c|c|c|c|c|c|}
\hline & $\begin{array}{c}\text { Temp. of the } \\
\text { removal } \\
\text { chamber }\left({ }^{\circ} \mathrm{C}\right)\end{array}$ & $\begin{array}{l}\text { Temp. of the } \\
\text { building bed } \\
\left({ }^{\circ} \mathrm{C}\right)\end{array}$ & $\begin{array}{c}\text { Layer } \\
\text { thickness } \\
(\mathrm{mm})\end{array}$ & $\begin{array}{c}\text { Hatch } \\
\text { distance } \\
(\mathrm{mm})\end{array}$ & $\begin{array}{c}\text { Scanning } \\
\text { speed fill } \\
(\mathrm{mm} / \mathrm{s})\end{array}$ & $\begin{array}{c}\text { Laser } \\
\text { power fill } \\
(\mathrm{W})\end{array}$ & $\begin{array}{c}\text { Scanning speed } \\
\text { contour/edges } \\
(\mathrm{mm} / \mathrm{s})\end{array}$ & $\begin{array}{c}\text { Laser power } \\
\text { contour/edges } \\
\text { (W) }\end{array}$ \\
\hline $\begin{array}{l}\text { Experimentally } \\
\text { determined } \\
\text { parameters }\end{array}$ & 125 & 125 & 0.15 & 0.25 & 3500 & 31.5 & 1500 & 10.7 \\
\hline $\begin{array}{l}\text { Manufacturer } \\
\text { specified } \\
\text { parameters }\end{array}$ & 115 & $120-125$ & 0.15 & 0.25 & 4500 & 35 & 1500 & 20 \\
\hline
\end{tabular}

TABle 10: Length $(L O)$ of the test specimens.

\begin{tabular}{lccc}
\hline & Total average $(\mathrm{mm})$ & Reference value $(\mathrm{mm})$ & Percentage difference $(\%)$ \\
\hline Specimen 1 & 112.05 & 115 & $3 \%$ \\
Specimen 2 & 112.57 & 115 & $2 \%$ \\
Specimen 3 & 112.95 & 115 & $2 \%$ \\
Specimen 4 & 112.35 & 115 & $2 \%$ \\
Specimen 5 & 112.13 & 115 & $2 \%$ \\
\hline
\end{tabular}

higher, than the one specified by the manufacturer almost. It is known that testing conditions of temperature and strain rate do affect the elongation to failure of materials [24]. For instance, elongation at break increases with increasing tem- perature, while slow testing allows a polymer to relax, which results in higher values of elongation to failure [24]. The test conditions in this case were standard in respect of these two parameters, and the large difference between the results 
TABLE 11: Width $(W)$ of the gauge length of the test specimens.

\begin{tabular}{lccc}
\hline & Total average $(\mathrm{mm})$ & Reference value $(\mathrm{mm})$ & Percentage difference $(\%)$ \\
\hline Specimen 1 & 5.32 & 6 & $11 \%$ \\
Specimen 2 & 5.67 & 6 & $5 \%$ \\
Specimen 3 & 5.83 & 6 & $3 \%$ \\
Specimen 4 & 5.54 & 6 & $8 \%$ \\
Specimen 5 & 5.47 & 6 & $9 \%$ \\
\hline
\end{tabular}

TABLE 12: Overall width (WO) of the test specimens.

\begin{tabular}{lccc}
\hline Specimen & Total average $(\mathrm{mm})$ & Reference value $(\mathrm{mm})$ & Percentage difference $(\%)$ \\
\hline 1 & 18.28 & 19 & $4 \%$ \\
2 & 18.65 & 19 & $2 \%$ \\
3 & 18.75 & 19 & $1 \%$ \\
4 & 18.33 & 19 & $3 \%$ \\
5 & 18.21 & 19 & $4 \%$ \\
\hline
\end{tabular}

obtained in this work and those given by the manufacturer cannot be explained away. However, it is noted that similar large differences have been observed elsewhere [14]. This raises a need for further investigation of the powder and testing of built specimens to establish the content and vet the mechanical properties of the new PLS material (Laser PP CP 60). Figure 5 shows bar chart plots of the experimental values of stiffness for each of the five specimens tested.

It is evident from the figure that specimen 2 had the highest Young's modulus, followed by specimen 5, which was followed by specimen 4 and then specimen 3 . Specimen 1 had the least value of Young's modulus.

Figure 6 shows bar chart plots of the experimental values of percentage elongation for each of the five specimens tested.

The order of the specimens in this figure in descending order is; specimen 5 , specimen 3 , specimen 2 , specimen 4 , and lastly specimen 1 .

Figure 7 shows bar chart plots of the experimental values of ultimate tensile strength for each of the five specimens tested.

The order of the specimens in this figure in descending order is specimen 5 , specimen 2 , specimen 3 , specimen 1 , and lastly specimen 4 .

For applications requiring high Young's modulus, the process parameters for specimen 2 are recommended. Similarly, for applications necessitating high percentage elongation, the process parameters for specimen 5 are proposed. Lastly, for applications requiring high ultimate tensile strength, the process parameters for specimen 5 were the most suitable. In conclusion, in this preliminary testing, it was decided that the best process parameters for Laser PP CP 60 are as summarized in Table 7, in which is also contained values recommended by the manufacturer. It is noted from the table that these experimentally determined values are very similar to the process parameters provided by the manufacturer, except for the removal chamber temperature. It was, however, decided that further research needed to be conducted whereby only one of the process parameters would be varied at a time, while keeping all others constant.
It was observed that Laser PP CP 60 is characterized by relatively low ultimate tensile strength, with significantly high percentage elongation.

4.3. Surface Roughness of Built Test Specimens. Table 8 provides data on surface roughness for specimens $1,2,3,4$, and 5 for both the top and bottom surfaces. Average values and standard deviations are also presented in the table and comparison made using the bar charts shown by Figures 8 and 9.

Figures 8 and 9 show the bar chart plots of surface roughness based on the parameter $R a$, for the top and bottom surfaces of the five specimens tested here, respectively.

The results show that specimen 4 had the smoothest top surface, followed by specimen 3 , then specimen 1 . Specimen 5 came fourth, while specimen 2 had the roughest top surface. The results show that specimen 4 had the smoothest bottom surface, followed by specimen 2 , then specimen 5 . Specimen 1 came fourth, whereas specimen 3 had the roughest bottom surface. Considering polyamide 12 grade PA 2200 from EOS $\mathrm{GmbH}$ as the reference material, as it is by far the most widely used polymer in PLS, then the surface roughness $(R a)$ of polymers should be approximately $15 \mu \mathrm{m}$ [25]. Specimen 2 gives values of mean arithmetic deviation, of the bottom surface $(15.038 \mu \mathrm{m})$, that are closest to the selected reference value. The difference for this specimen and others implies the need for postprocess grinding to improve the surface finish of components manufactured using Laser PP CP 60.

The process parameters utilized for specimen 4 gave the best top and bottom surface roughness, since the sample yielded the least value of $R a$. Therefore, for low surface roughness, Laser PP CP 60 should be printed using the process parameters set to produce specimen 4 as summarized in Table 9. However, further surface roughness testing should be done on three-dimensional parts where roughness is also measured on vertical surfaces across layers, since surfaces at angles present the worst surface roughness because of the staircase effect across layers. 


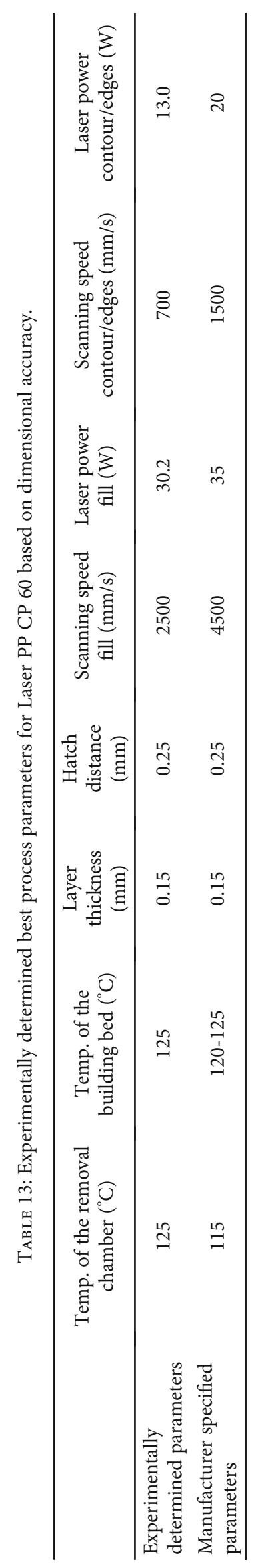


4.4. Dimensional Accuracy of the Printed Parts. Dimensional accuracy was determined by measuring the length (LO), the width (W), and the overall width (WO) of the specimen. The data obtained is presented in Tables 10, 11, and 12, respectively.

The data for the overall width $(W O)$ for each specimen is presented in Table 12.

The measurements to test for dimensional accuracy presented in this section show that there were slight variations between the experimental and reference design values as represented in the columns for percentage difference in Tables 10, 11, and 12. The slightly lowerdimensional variations of the printed parts are likely to have been due to the shrinkage of the printed parts. Polymeric materials manufactured using PLS tend to experience shrinkage, which affects the dimensional accuracy. Therefore, it is imperative to determine the magnitude of shrinkage of a particular material of interest. This value should be considered when sketching and slicing the CAD data. The value is referred to as the scaling factor. In this regard, a scaling value of about 1.8 was considered in this analysis. The value was selected based on previous studies on Laser PP CP 75 [14]. The fact of the small discrepancies indicates that the used scaling factor is acceptable when dealing with Laser PP CP 60 polypropylene powder. Considering the data presented in Tables 10, 11, and 12, the process parameters used for specimen 3, shown in Table 13, yielded the best results with the least overall percentage difference.

\section{Conclusion}

The following conclusions were deduced from this investigation:

(i) The most suitable temperature for both the building and removal chambers for Laser PP CP 60 powder is $125^{\circ} \mathrm{C}$

(ii) Processing of the new material was challenging because of problems of flowability, which affected the spreading of the powder. Besides, curling of the printed parts was observed, which caused the recoater blade to displace parts in the building bed. Hence, only flat tensile specimens were successfully printed

(iii) The process parameters that yielded the best mechanical properties for the laser PP CP 60 powder were $125^{\circ} \mathrm{C}, 125^{\circ} \mathrm{C}, 0.15 \mathrm{~mm}, 250 \mu \mathrm{m}$, $4500 \mathrm{~mm} / \mathrm{s}, 34.7 \mathrm{~W}, 1500 \mathrm{~mm} / \mathrm{s}$, and $21.3 \mathrm{~W}$ for the removal chamber temperature, building chamber temperature layer thickness, hatch distance, scanning speed fill, laser power fill, scanning speed contour, and laser power contour, respectively

(iv) The best process parameters were selected based on the specimen with the best ultimate tensile strength (v) Curling and poor geometrical accuracy were observed for all the specimens built. The material is not ready for commercial application

(vi) Following the operator's experience to set process parameters is not the best way

\section{Recommendations}

(i) Further research needs to be conducted to better determine the process parameters of laser PP CP 60 polypropylene powder following a schedule where only one of the process parameters is varied at a time and the others held constant. Besides, the experiment should be repeated for at least five tensile specimens, fabricated under the same processing parameters

(ii) As only flat tensile specimens were built here, printing of components with complex geometries should be undertaken in order to investigate the accuracy of printing with respect to small geometric changes of shape

\section{Data Availability}

Data in the text.

\section{Conflicts of Interest}

The authors declare that they have no competing interests.

\section{Acknowledgments}

The financial support from the South African Research Chairs Initiative of the Department of Science and Technology and National Research Foundation of South Africa (Grant No. 97994) and the Collaborative Program in Additive Manufacturing (Contract No. CSIR-NLC-CPAM-15MOA-CUT-01) is gratefully acknowledged. Thanks also to the Centre of Rapid Prototyping and Manufacturing (CRPM) for technical support.

\section{References}

[1] A. Dehghanghadikolaei, N. Namdari, B. Mohammadian, and B. J. J. O. S. Fotovvati, "Additive manufacturing methods: a brief overview," Journal of Scientific and Engineering Research, vol. 5, no. 3, pp. 123-131, 2018.

[2] A. Zolfagharian, M. A. P. Mahmud, S. Gharaie, M. Bodaghi, A. Z. Kouzani, and A. Kaynak, "3D/4D-printed bending-type soft pneumatic actuators: fabrication, modelling, and control," Virtual and Physical Prototyping, vol. 15, no. 4, pp. 373-402, 2020.

[3] R. D. Goodridge, C. J. Tuck, and R. J. M. Hague, "Laser sintering of polyamides and other polymers," Progress in Materials Science, vol. 57, no. 2, pp. 229-267, 2012.

[4] M. Schmid, A. Amado, and K. Wegener, "Polymer powders for selective laser sintering (PLS)," AIP Conference Proceedings, vol. 1664, no. 1, pp. 159993-160009, 2015.

[5] H. Zhang and S. LeBlanc, "Processing parameters for selective laser sintering or melting of oxide ceramics," in Additive 
Manufacturing of High-performance Metals and AlloysModeling and Optimization, vol. 10, no. 57pp. 1-44, IntechOpen, 2018.

[6] T. M. Marin, Selective Laser Sintering of Polyolefins (Master's Thesis), 2017.

[7] I. Flores Ituarte, O. Wiikinkoski, and A. Jansson, "Additive manufacturing of polypropylene: a screening design of experiment using laser-based powder bed fusion," Polymers, vol. 10, no. 12, pp. 1293-1293, 2018.

[8] M. B. Sagar and K. Elangovan, "Consolidation \& factors influencing sintering process in polymer powder based additive manufacturing," IOP Conference Series: Materials Science and Engineering, vol. 225, no. 1, pp. 012065-012075, 2017.

[9] J. P. Sequeira, V. Pharale, E. Preetham, and M. Krupashankara, "Studies on effect of process parameters on sintering of materials using laser assisted powder bed fusion process," i-Manager's Journal on Mechanical Engineering, vol. 8, no. 2, pp. 19, 2018.

[10] R. D. Goodridge, R. J. Hague, and C. J. Tuck, “An empirical study into laser sintering of ultra-high molecular weight polyethylene (UHMWPE)," Journal of Materials Processing Technology, vol. 210, no. 1, pp. 72-80, 2010.

[11] S. Singh, A. Sachdeva, and V. S. Sharma, "Optimization of selective laser sintering process parameters to achieve the maximum density and hardness in polyamide parts," Progress in Additive Manufacturing, vol. 2, no. 1-2, pp. 19-30, 2017.

[12] C. Y. Wang, Q. Dong, and X. X. Shen, "Research on warpage of polystyrene in selective laser sintering," Applied Mechanics and Materials, vol. 43, no. 20, pp. 578-582, 2011.

[13] S. Berretta, K. E. Evans, and O. Ghita, "Processability of PEEK, a new polymer for high temperature laser sintering (HT-LS)," European Polymer Journal, vol. 68, no. 1, pp. 243-266, 2015.

[14] J. Nsengimana, J. G. van der Walt, E. H. G. Langner, and D. J. de Beer, "Determining optimal scanning speed for laser sintering of cp75 polypropylene powder," RAPDASA Conference, vol. 20, no. 1, pp. 303-314, 2019.

[15] M. Schmid and K. Wegener, "Additive manufacturing: polymers applicable for laser sintering (LS)," Procedia Engineering, vol. 149, pp. 457-464, 2016.

[16] R. G. Kleijnen, M. Schmid, and K. Wegener, "Production and processing of a spherical Polybutylene terephthalate powder for laser sintering," Applied Sciences, vol. 9, no. 7, pp. 13011308, 2019.

[17] N. Mys, A. Verberckmoes, and L. Cardon, Expanding the material palette for Selective Laser Sintering: two production techniques for spherical powders. Paper presented in the 8th Bi-annual international conference on Polymers and Moulds Innovations (PMI 2018), University of Minho. Institute of Polymers and Composites, 2018.

[18] D. Drummer, D. Rietzel, and F. Kühnlein, "Development of a characterization approach for the sintering behavior of new thermoplastics for selective laser sintering," Physics Procedia, vol. 5, no. 1, pp. 533-542, 2010.

[19] G. M. Craft, Characterization of Nylon-12 in a Novel Additive Manufacturing Technology, and the Rheological and Spectroscopic Analysis of PEG-Starch Matrix Interactions, Graduate Thesis, University of South Florida, 2018.

[20] L. J. Tan, W. Zhu, and K. Zhou, "Recent progress on polymer materials for additive manufacturing," Advanced Functional Materials, vol. 30, no. 43, pp. 1-18, 2020.
[21] American Society For Testing And Materials, D638 - 14. Standard Test Method for Tensile Properties of Plastics, vol. 17, ASTM International, 2014.

[22] R. Majchrowski and K. Morawski, "Surface roughness measurements method based on non-contact optoncdt sensor," XXI IMEKO World Congress "Measurement in Research and Industry”, vol. 21, no. 1, pp. 1-7, 2015.

[23] G. Farkas and Á. Drégelyi-Kiss, "Measurement uncertainty of surface roughness measurement," IOP Conference Series: Materials Science and Engineering, vol. 448, no. 1, pp. 012020-012033, 2018.

[24] H. F. Schiefer and R. S. Cleveland, "A critical study of some factors affecting the breaking strength and elongation of cotton yarns," Journal of Research of the National Bureau of Standards, vol. 27, no. 3, pp. 325-342, 1941.

[25] J. Guo, J. Bai, K. Liu, and J. Wei, "Surface quality improvement of selective laser sintered polyamide 12 by precision grinding and magnetic field-assisted finishing," Materials \& Design, vol. 138, no. 3, pp. 39-45, 2018. 